\title{
Intangible Search, Searching the Intangible: The Project E.CH.I. and the Inventarisation of Intangible Cultural Heritage
}

\author{
Emanuel Valentin \\ Free University of Bozen-Bolzano, Italy \\ Email: emanuel.valentin@education.unibz.it
}

\section{Doi:10.5901/ajis.2013.v2n8p113}

\section{Abstract}

The Interreg project "E.CH.I. Italo-Swiss Ethnographies for the Valorisation of Intangible Heritage" builds on the UNESCO Convention for the Safeguarding of Intangible Heritage (2003) which has been adopted in 2007 by Italy and in 2008 by Switzerland. In this project seven partner institutions from Italy and Switzerland coped with the challenges of identifying and documenting intangible cultural expressions in the border area between these two countries. In order to create a common denominator in the methodological approach a series of workshops have been organized, which were dedicated to audio and video techniques but also to techniques of documentation. Furthermore, as another important instrument of standardization an internet-based inventory has been developed, in which all documentations produced by the project partners have been catalogued. The inventory, which counted 242 documentations in June 2013 and which is the main result of the project, can be viewed online under the name "Intangible Search". This article focuses on the insights gathered during the project E.CH.I. and the development of such a common inventory.

\section{Introduction}

With the "intangible turn" of the world heritage discussion which had its climax in UNESCO's Convention for the Safeguarding of the Intangible Cultural Heritage, the intangible cultural heritage became a focus of present cultural politics (Munjeri, 2004; Vecco, 2010). This Convention was adopted on 17th October 2003 in Paris and entered into force on $20^{\text {th }}$ April 2006 after it had been ratified by thirty member states. This requirement, as defined by Article 34 , has been reached in only twenty-eight months. By $10^{\text {th }}$ April 2013 the Convention had been ratified by 153 states, joined by Finland as the last Nordic country on $21^{\text {st }}$ May 2013. Never before a Convention has been so popular on international levels (Alivizatou, 2012a, p. 32; Blake, 2006, p. 1).

The purposes of this Convention are "a) to safeguard the intangible cultural heritage; b) to ensure respect for the intangible cultural heritage of the communities, groups and individuals concerned; c) to raise awareness at the local, national and international levels of the importance of the intangible cultural heritage, and of ensuring mutual appreciation thereof; d) to provide for international cooperation and assistance" (UNESCO, 2003, Art. 1). But what does "intangible cultural heritage" mean? UNESCO's 2003 Convention defines this new kind of heritage as "the practices, representations, expressions, knowledge, skills - as well as the instruments, objects, artefacts and cultural spaces associated therewith - that communities, groups and, in some cases, individuals recognize as part of their cultural heritage. This intangible cultural heritage, transmitted from generation to generation, is constantly recreated by communities and groups in response to their environment, their interaction with nature and their history, and provides them with a sense of identity and continuity, thus promoting respect for cultural diversity and human creativity" (UNESCO, 2003, Art. 2.1). According to this definition intangible heritage is manifested in the following domains: "a) oral traditions and expressions, including language as a vehicle of the intangible cultural heritage; b) performing arts; c) social practices, rituals and festive events; d) knowledge and practices concerning nature and the universe; e) traditional craftsmanship" (UNESCO, 2003, Art. 2.2).

The 2003 Convention is also the starting point of the Interreg-Project "E.CH.I. Italo-Swiss Ethnographies for the Valorisation of Intangible Heritage" which was part of the Operational Programme Italy-Switzerland 2007-2013. This article derives from the experience which I have gathered within the E.CH.I. project as researcher on account of one of its project partners, the Museum Ladin Ćiastel de Tor in the Autonomous Region Bozen-South Tyrol. I have described this research in a contribution to the forthcoming book Antropologia e beni culturali nelle Alpi (Anthropology and cultural goods in the Alps) edited by Laura Bonato and Pier Paolo Viazzo (Bonato \& Viazzo, 2013; Valentin, 2013). Hence, the article sheds light primarily on the insights derived from my work done on account of one project partner reflecting my 
personal opinion which may differ from that of other partners within this project.

In this article I will highlight the news introduced with the 2003 Convention in contrast to former UNESCO programmes on intangible cultural heritage and resume some problems and paradoxes of UNESCO's concept of intangible cultural heritage as emphasised by critical observers, especially concerning one measure of safeguarding intangible heritage proposed by UNESCO, that is the creation of lists and inventories. I will then proceed to describe the E.CH.I. project and one of its main outcome, the Intangible Search, which is an online inventory of intangible cultural heritage in the border area between the Swiss and the Italian part of the Alps. In the conclusions I will discuss critically this inventorial experience which may add further insights to the debate on the question if culture can or should be inventoried.

\section{UNESCO and intangible heritage}

There are fundamental differences between the definition of intangible cultural heritage as proposed by the 2003 Convention and UNESCO's former programmes on intangible heritage, like the "Recommendation on the Safeguarding of Traditional Culture and Folklore" adopted in 1989 and the "Proclamation of Masterpieces of the Oral and Intangible Heritage of Humanity, which was introduced in 1997. While the latter "was significantly problematized, as it seemed to relate more to the areas of fine art or music than to popular and traditional culture" (Alivizatou, 2012a, p. 33), the definition of intangible heritage in the 2003 Convention had to be sufficiently holistic and inclusive not only to cover an evolutionary and dynamic dimension but also by attributing a more active role to the people creating, maintaining and transmitting it (Blake, 2006, p. 31). The purely archival approach towards the protection of traditional culture of the 1989 Recommendation was substituted with the 2003 Convention by an approach which brought into the foreground the active participation of communities and their important role in the transmission of their heritage.

"Ideas of living heritage", "heritage in danger", "community participation", and "authenticity" - these are the main characteristics of the "new intangible heritage narrative" as identified by Alivizatou (Alivizatou, 2012a, p. 35ff.).

The "ideas of living heritage" refer to the fact that intangible cultural heritage as expressed in the 2003 Convention consists of cultural practices which are still alive and are still practiced by communities. Because of "its living and constantly evolving nature" (Alivizatou, 2012a, p. 35), intangible heritage changes with its communities. This, in turn, may imply an apparent contradiction between the ideas of living heritage and the need for safeguarding it.

Another issue are the apparent threats to which intangible heritage is exposed. "Globalisation" and "social transformations" are identified in the Preamble of the Convention as factors representing a danger to intangible heritage (UNESCO, 2003). Even if the Convention inherits ideas of loss (or the fear of it) and its "preservationist ethos" (Alivizatou, $2012 a$, p. 37) from former heritage discourses, it gives ground to the idea of "safeguarding" as "new salvage paradigm for living heritage" (Alivizatou, 2012a, p. 37) which replaces notions of "conservation", "preservation" and "protection" in favour of notions of "flourishing" and "sustainable development". Hence, there is no evident contradiction between the ideas of living heritage and the need for safeguarding it, as stated above.

One of the key dimensions which distinguishes the 2003 Convention from former UNESCO instruments is "community participation". This participation is implicitly contained in the definition of intangible cultural heritage as it "means the practices, representations, expressions, knowledge, skills [...] that communities, groups and, in some cases, individuals recognize as part of their cultural heritage (UNESCO, 2003, Art. 2, §1, accentuation by the author). Throughout the convention there are several references to the participation of communities in the safeguarding process. In the Preamble it is recognised that communities, "in particular Indigenous communities, groups and, in some cases individuals, play an important role in the production, safeguarding, maintenance and recreation of intangible heritage" (UNESCO, 2003). Article 11 emphasises this point again in explicit relation to State Parties: "Each State Party shall [...] identify and define the various elements of the intangible cultural heritage present in its territory, with the participation of communities, groups and relevant nongovernmental organizations" (UNESCO, 2003). Article 15 is dedicated most explicitly to community participation: "Within the framework of its safeguarding activities of the intangible cultural heritage, each State Party shall endeavour to ensure the widest possible participation of communities, groups and, where appropriate, individuals that create, maintain and transmit such heritage, and to involve them actively in its management" (UNESCO, 2003). Unfortunately, the Convention doesn't contain any guidelines on how such participation process should be realised.

Community participation implies that the definition of which cultural practices may be identified as intangible heritage is up to the communities themselves, hence there cannot be fixed criteria to define "authenticity" of intangible heritage without risking an ethnocentric bias. The 2003 Convention had to overcome the problematic nature of the world 
heritage concept by finding a balance between universalism of the world heritage approach on the one hand and the relativism of approaches to authenticity on the other (Alivizatou, 2012a, p. 31). Nevertheless, "although never mentioned in the official documents, authenticity is very much present in the intangible heritage discourse. [...] Fears of acculturation, commercialisation, or folklorisation, for example, reveal an institutional will to protect intangible heritage from the threats of modernity, suggesting that the latter will harm original, authentic, and uncontaminated traditions" (Alivizatou, 2012a, p. 39). According to Alivizatou, this shows up another paradox of UNESCO's concept of intangible heritage: „while acknowledging that intangible heritage is living and constantly changing, the normative framework of UNESCO is designed in such a way as to impede its modernity-engendered transformation" (Alivizatou, 2012a, p. 39).

The system of safeguarding foreseen by the 2003 Convention is based on lists aimed at the identification and valorisation of intangible heritage. Articles 16 and 17 prescribe the creation of two international lists. One is the Representative List of the Intangible Cultural Heritage of Humanity, the other is the List of Intangible Cultural Heritage in Need of Urgent Safeguarding. While the first shall "ensure better visibility of the intangible cultural heritage and awareness of its significance, and [...] encourage dialogue which respects cultural diversity" (UNESCO, 2003, Art. 16), the second one shall be created "[w] th a view to taking appropriate safeguarding measures" (UNESCO, 2003, Art. 17). If, on one side, the process of listing, which lies on the basis of every process of heritagisation, has been criticised as supporting elitist and hierarchical thinking, on the other side it has been recognised as a necessary instrument, firstly for the identification and secondly for the safeguarding of cultural practices.

As it was the case with the World Heritage List based on UNESCO's 1972 Convention, the elements proposed to be inserted into the Representative List of the Intangible Cultural Heritage of Humanity or the List of Intangible Cultural Heritage in Need of Urgent Safeguarding have to be previously inscribed into national inventories which the 2003 Convention regards as important instrument ensuring "identification with a view to safeguarding" (UNESCO, 2003, Art. 12). This led to a real competition among the State Parties in the creation of inventories since the concept of inventory is based on institutional, administrative, technical and scientific models which are more familiar to national governments as the more abstract concept of safeguarding (ASPACl, 2011, p. 12).

\section{Problems and paradoxes of UNESCO's concept of intangible cultural heritage}

Several heritage theorists and practitioners have underlined different problems and paradoxes on UNESCO's concept of intangible cultural heritage. International mobilisation and involvement of national governments in the areas of cultural diversity, traditional knowledge and popular lifeways, but also the inherent institutionalisation of culture and its ethnocentric bias have been severely doubted (Kirshenblatt-Gimblett, 2004; Nas, 2002). While some discussed intangible heritage as a remedy to the loss of identity characterising the postmodern era (Nas, 2002), others discussed it as a sort of "metacultural production" (Kirshenblatt-Gimblett, 2004). A radical impact can result from governmental and international involvement on how communities perceive their tradition. This is where also the debate about the invention of tradition (Hobsbawm \& Ranger, 1983) comes in again. If the safeguarding measures according to UNESCO are global measures with the aim of counteracting globalisation (Nas, 2002), "[h]ow is it possible then for local, site-specific and community-related expressions to be asked to meet the same global and vague criteria in the name of cultural diversity and anti-standardisation?" (Alivizatou, 2012b, p. 10). Another problematic issue, which applies to the whole heritage discourse, is the idea of exclusion. "In addition to leaving out popular, global, and hybrid culture, the intangible heritage discourse creates a problematic relationship between a dominant national and a more marginalised minority heritage. The traditions of religious, ethnic, or cultural minorities are often left out of the official national narrative" (Alivizatou, 2012a, p. 41).

One of the most criticised things of the 2003 Convention are the lists and inventories which are proposed as primary measures of safeguarding. The concentration of resources on inventories by the side of the State Parties represent for some observers nothing else than a strategy for avoiding real measures of safeguarding which allow to just limit to purely symbolic interventions (Kirshenblatt-Gimblett, 2004). The priority laid on the creation of lists has been judged as objectifying, segmenting and simplifying cultures (Alivizatou, 2012a, p. 42) since it is translating cultural complexities into lists which consist of standardised descriptions recalling a naturalistic procedure of classification condemned as "positivistic illusion" (ASPACl, 2011, p. 14). Focussing on inventories has been seen contemporarily as technocratic, since it may become an exercise focussed primarily on information management, and anachronistic, since it is inspired in the salvation ethnography of early anthropology which had the primary scope to document primitive cultures in their entirety in order to prevent their complete loss (Brown, 2005). "Cultural decontextualisation", "alienation", "fossilisation", "bureaucratisation of culture" are some of the terms going along with these critiques (Brown, 2005; Nas, 
2002). Once cultural practices have been identified and listed, they may be exposed to interests, instrumentalisation, appropriation and commercialisation by users of these inventories, processes which cannot be predicted (Schuster, 2002). This raises problematic questions about intellectual property rights, since there is no international consensus about how rights on traditional knowledge can be secured (Anderson, 2010). Finally, inventories may be seen by State Parties as elements which give them visibility and prestige, while to those who work closely with communities they may appear focussed merely on metacultural representations than on the culture and its bearers (Kirshenblatt-Gimblett, 2004; Kurin, 2007; Nas, 2002).

\section{The project "E.CH.I. Italo-Swiss Ethnographies for the Valorisation of Intangible Heritage"}

The project "E.CH.I. Italo-Swiss Ethnographies for the Valorisation of Intangible Heritage" builds on the mentioned UNESCO convention of 2003 which has been adopted by Italy in 2007 and by Switzerland in 2008. Lead partner of this project was the Archive of Ethnographies and Social History (Archivio di Etnografie e Storia Sociale AESS) of the Region Lombardy. Aside from this further six partner institutions participated in the project. On the Italian side these have been the Regional Office for Ethnology and Linguistics (Ufficio Regionale Etnologia e Linguistica or Bureau Regional pour l'Ethnologie et la Linguistique BREL) of the Autonomous Region Aosta Valley, the Department Museums and Cultural Heritage (Settore Musei e Patrimonio Culturale) of the Region Piedmont and the Museum Ladin Ciastel de Tor as representative of the Regional Museums in the Autonomous Region of Bozen-South Tyrol (Musei Provinciali Altoatesini). On the Swiss side the partners have been the Médiathéque Valais Martigny (Canton Valais), the Centre of Dialectology and Ethnography (Centro di Dialettologia ed Etnografia) in the Canton Ticino and Polo Poschiavo in the Canton Grisons.

The authors of the E.CH.I. project showed a big deal of creativity in the development of the acronym of the project. E.CH.I. is on one side the abbreviation of "Italo-Swiss ethnographies" which refers both to the ethnographic method applied in the documentation of intangible heritage and to the territories in the border area between Switzerland $(\mathrm{CH})$ and Italy (I), on which the project was focussed. On the other side the acronym refers to the mythology of the nymph Echo. In the description of the project application we can read:

"Ovid reports that Echo was a nymph particularly talented in the art of narration. She was so talented that Zeus commissioned her to distract his wife Hera during his frequent extramarital adventures. Hera, after uncovering the swindle, did not appreciate this abusive use of the art of narration, deprived the nymph of her talent and condemned her to repeat only the last words of the sentences she heard. [...] Echo, hence, is per antonomasia the fragment of a tale. And echoes are therefore "voices" which reverberate, rebound and dangle after each other - between rocky faces and valley scenarios - telling cuttings of a tale which, within the sonorous landscape, have undergone variations of effects, of forms, of interpretations and also of contents" (E.CH.I. project application, p. 1).

The echoes (in Italian echi), to which the described project is referring, are resound voices and episodes of tales in Alpine spaces which can adopt different variations, forms, contents and interpretations. The project E.CH.I. was dedicated to these immaterial fragments in the territories between Italy and Switzerland and has been concentrated on the following activities «in order to safeguard and to hand on cultural practices and traditional knowledge» (E.CH.I. project application, p. 6):

a. Identification: The identification of the intangible cultural heritage occurs through involvement of the community and the realisation of research projects which support the elaboration of dynamic territorial inventories.

b. Documentation: The intangible heritage is a living heritage. As such it is subject to constant transformation and change. Hence, intangible heritage cannot be safeguarded directly but can be fixed through the production of documentations, which allow to verify the evolutions and to understand processes of change.

c. Conservation: Primary goal of the conservation of the documentations is to facilitate the access to the documented knowledge through the creation of dynamic catalogue systems which allow a continuing implementation of the information.

d. Dissemination: The intangible heritage is expressed in manifestations of individual and collective intellectual creativity, which have to be safeguarded through recognition of the rights of informants while securing the protection and the access to documentary collections. For this reason the international scientific community has to be encouraged in adopting a code of ethics which guarantees the respect of traditional cultures and of their bearers. The transmission of intangible heritage can be promoted by programmes and initiatives which help the bearers of tradition and foster the renovation through new forms of creativity.

e. Promotion: The value of intangible heritage shall be disseminated as much as possible through the organisation of events such as fairs, festivals, seminars and workshops, through media, radio, television and 
through the realisation of products with educative scope which can be used in schools, cultural institutes, etc. (E.CH.I. project application, p. 6-7).

On the basis of the mentioned activity fields the project follows a common strategy "which supports the communities in their response to the homologising pressure which globalisation exerts on peculiarities, on cultural and linguistic pluralities and on the continuity of some traditional activities, especially in border areas" (E.CH.I. project application, p. 8).

In order to create a common denominator in the methodological approach a series of workshops have been organised, which were dedicated to audio and video techniques but also to documentation techniques of certain categories of intangible heritage, like festivals or traditional craftsmanship. Furthermore another important instrument of standardisation has been developed. This was an internet-based inventory called Intangible Search, in which all documentations produced by the project partners have been catalogued. In the next section we will have a closer look at this inventory.

\section{Intangible Search: The inventory of the E.CH.I. project}

One of the main outcomes of the project was the "Intangible Search: Inventory of cultural heritage" which is publicly accessible online. ${ }^{1}$ Since every project partner catalogued all the documentations produced by using this online tool, in June 2013 it counted 242 documentations.

If we open the web page, we get a first overview of the inventory's structure on the start page and we are offered a broad array of possibilities to browse through the documentations contained in it. An inevitable eye-catcher is the big banner which shows a picture of a cultural practice which has been documented. As a sort of appetiser, the user can thumb through some of such pictures, showing a few examples of the numerous documentations contained in the inventory, like the art of violin-making of Cremona, the art of lace-making of the Canturino area, transhumant shepherds in the Lombardy region, or the Carnival of Bagolino and Étroubles.

Below the banner we find different possibilities to explore the inventory, either by showing its contents as a list, as a map or by categories. If we choose the list, we will get all file cards contained in the inventory ordered alphabetically by their title. If we are more interested in the geographical distribution of cultural practices, we may prefer the map view from which to choose the file card we want to look at more closely. The third possibility is to choose one of the five categories "arts and entertainment", "oral traditions", "rituals", "naturalistic knowledge" and "technical knowledge", which represent the categories of intangible heritage as defined by UNESCO's 2003 Convention. Practical experience has shown that it is not always possible to clearly associate a cultural practice to only one category. It may be the case that if we focus on different elements of a cultural practice it might be attributed to two or even more categories. The Intangible Search does not allow to associate a practice to more than one category. This might be avoided by splitting a file card, focussing the description of every file card on specific elements which we want to associate to a certain category, and linking these related file cards to each other.

There are other ways to explore the inventory. We can use either the search function to find a keyword in the whole inventory or just in certain categories, or we can choose a tag from a list getting all file cards which match with it. Additionally, we can click on small icons with portraits of some people involved in the documentation of cultural practices. By doing so, we get a small biography of that person and the file cards with the documentations associated with that person.

Once the user has identified the cultural practice he is interested in, he has the possibility to see further details and access the documentations produced by opening the associated file card. On the top of this file card we get first of all a multimedia gallery containing pictures, audio recordings and/or videos. The gallery shows us documents related to a specific year in which they have been produced. Some file cards contain also archival materials which can be shown by browsing through a timeline below the gallery which allows to access multimedia files according to the year of its production or of the production of the source document they reproduce. The file card contains furthermore a textual description of the cultural practice with considerations on its transmission, involved communities, existing actions of valorisation and safeguarding measures. On the left side, the user finds the information to which heritage category the practice has been associated with, some related tags, its geographical and temporal localisation, and who are the protagonists involved. On the right side, there are some references to the described cultural practice (bibliography,

\footnotetext{
${ }^{1}$ Intangible Search, http://www.intangiblesearch.eu/
} 
websites, archives, etc.), information about related material goods, the author(s) or responsible institution who produced the file card and the date of publication. Furthermore, there is the possibility to share the file card on the most popular social networks, like facebook and twitter.

Last but not least, since E.CH.I. is understood as a community-based and participatory project, anyone can make suggestions and indicate cultural practices which communities may identify as their heritage. By clicking the "suggest" button an online form is opened through which contact details, a message and even files (pictures, pdf or word files) can be uploaded.

So far I have described the online inventory as it is accessible by the public. But what lies on the backstage of this inventory? Behind the inventory lies a password protected online database which is accessible only by authorised people, i.e. institutions and researchers involved directly in the E.CH.I. project. This database represents an attempt to deliver an instrument of standardisation for online cataloguing of all produced documentations. While the information in the online inventory accessible to the public is limited to more general information, the online database from which the Intangible Search is fed contains additional detail information needed for a more exhaustive documentation of a cultural practice. Without going into details, I just would like to give a summary outline of which information is given in this online database. Each cultural practice catalogued in the system is associated to one category of intangible heritage and tagged with keywords. In addition to a general denomination of the cultural practice also its local (emic) denomination is documented. The data about the geographical localisation of the documented element includes also GPS coordinates which are shown on an embedded map by Google Maps. Without knowing the exact GPS coordinates it is also possible to delimit a certain area or territory by drawing lines directly on the map. Furthermore, a textual description of the spatial movements can be added, which may be relevant for the description of processions or similar practices, for example. Along the spatial data also data about the recurrence is inserted, i.e. if it is a yearly or another periodical event, which occasions (religious, natural, lifecycle, etc.) may be related to it, and if the practice is still living or if it is not practiced anymore. It follows a textual description of the practice, historical notes, notes on associated tangible and intangible goods, the persons met during the documentation, notes on the communities involved, the transmission and actions of valorisation and safeguarding which may apply. Last but not least, multimedia files like pictures, audio files, videos, etc. can be uploaded. For each uploaded file some information can be added, like a description, the author, date etc. and if the file may be published on the Intangible Search or not.

\section{Conclusions}

This article resumes some new tendencies in the approach to heritage as introduced by UNESCO's 2003 Convention for the Safeguarding of Intangible Cultural Heritage when compared with former programmes on intangible heritage. There are some important critical points of the 2003 Convention, especially as regards to lists and inventories proposed by UNESCO as primary safeguarding measure. Drawing on the case of the project "E.CH.I. Italo-Swiss Ethnographies for the Valorisation of Intangible Heritage", I described a recent project experience in the implementation of an online inventory like the Intangible Search. As a conclusion, I would like to discuss critically this inventory which may add further insights to the debate on the question if culture can or should be inventoried and if so, how this can be done without falling into essentialising, objectifying and simplifying discourses.

The collection, the representation and interpretation of knowledge ask for participative involvement of the community and an open dialogue. The 2003 Convention does not deliver clear guidelines on how such a participatory process could be designed and I doubt that this would have any positive impact due to the very heterogeneous situations anthropologists encounter in the field even while working within the same community. The very different approaches and degrees of participation we find in different inventories in Europe, Asia, Nord and South America (ASPACl, 2011, p. 91ff.) is further evidence for this argument. Within the E.CH.I. project it might have been a good choice to organise - together with the more technical workshops on documentation, audio and video techniques - a workshop dedicated to communitybased and participatory instruments in order to align methodologically all project partners. But even with such an alignment it would have been impossible to have the same participatory procedure for every project partner without creating an unnatural research situation. I think much could be done methodologically if best practice experiences would be shared more intensively among people involved in similar projects.

Furthermore, an online form for heritage suggestions and social network plugins on the Intangible Search may proof to be incentives for increased involvement of communities. But we have to be conscious about the fact that these instruments are addressed only to people with access to those technologies and who have appropriate technical literacy. More often than not, the bearers of traditional knowledge (like seniors for example) are not familiar at all with such 
modern instruments of communication and would depend on "technological brokers" in order to be "heard". On the other hand, this could also proof to be an incentive for intergenerational transmission of cultural heritage (or at least exchange of knowledge and skills), when, for example, a grandparent tells a cultural practice so far unknown to a grandchild who in turn inserts the suggestion on the website on account of the grandparent.

A similar argument applies also to the accessibility of the heritage documentations. For sure, the fact that users have the possibility to access the contents of the inventory in their own language is a minimum requirement. In fact, the Intangible Search can be explored in five different languages, offering not only languages like English, French, German or Italian but also a minority language like the Gherdëina, a variation of the Raetoroman or Ladin language which is spoken in Gröden Valley (Val Gardena) - territory on which I did my research on account of the Museum Ladin (Valentin, 2013). Digital archives have certainly a lot of advantages and open up completely new possibilities regarding worldwide collaboration, accessibility, exchange and promotion. But as long as there will be people with restricted access to this new technological instruments we should have also alternative mediums for the storage of documentations as complementary instruments to electronic mediums.

The fact that new technologies ease worldwide access and communication is closely related also to problems of publication. Up to which point things can be published and what happens with sensitive data? Who should actually have the right to access which data? And finally: who should decide about this? At the moment, the online inventory behind Intangible Search does not offer the possibility to define which information will be published on the public website. Up to now, it is possible only with the multimedia files to define if they can be published or not.

The translation of intangible cultural heritage into digital archives appears to me as a logical consequence due to the accelerating development of new technologies which made worldwide realtime collaboration and promotion much easier. The preservationism which may be justified in the case of monuments or archaeological sites is unjustified in the case of the intangible heritage. We can't - and I would also say we shouldn't - counteract the change and transformation of intangible cultural heritage through documentation and display in online inventories. Even in UNESCO's concept of safeguarding this is not foreseen. Traditions, festivals and rituals can't be embalmed. What we can conserve there is at most snap-shots of these practices on video, audio and photographs. We should think, as Alivizatou suggests, beyond notions of decay, salvation or loss and recognise cultural change as new value in coping with cultural heritage (Alivizatou, 2012a). The Intangible Search tries to avoid a static description of a cultural practice through the timeline which allows to browse the multimedia files according to their year of production. Unfortunately, this timeline does not apply to the textual description which in turn assumes the characteristics of an unchanging inscription. If such a description is not updated we would seem to confirm the static nature of a cultural practice and if it is updated without saving former versions of such descriptions we would lose precious data for reconstructing the evolution of that heritage.

It remains the question if culture can or should be inventoried and if so, how this can be done without falling into essentialising, objectifying and simplifying discourses. In my personal opinion these two questions can both be answered positively. If postmodern anthropology claims to be able to write books about culture which are free from essentialism, objectivism and simplification, why then should this be different with inventories? Doing research on culture, independently from the form of its publication, is completely legitimate as long as fundamental ethical and professional aspects are taken into account and respected. The intangible heritage as highlighted by the UNESCO Convention bears interesting challenges and new potentials for anthropological research. I believe that we as inventorying anthropologists still can remain on neutral grounds as long as we do not aspire to reach an inscription on one of UNESCO's proposed lists as outcome of our inventorying practices, which of course may be the result of them even without our intention. Only through active participation and participative observation, that is actually by doing our job, in this new context of multinational cultural politics of intangibility we can take care that these inventorying practices become as scientifically valid like other variants of anthropological research might be.

\section{References}

Alivizatou, M. (2012a). Intangible Heritage and the Museum: New Perspectives on Cultural Preservation. Walnut Creek: Left Coast Press.

Alivizatou, M. (2012b). The Paradoxes of Intangible Heritage. In M. L. Stefano, P. Davis, \& G. Corsane (Eds.), Safeguarding Intangible Cultural Heritage: Touching the Intangible (pp. 9-21). Boydell \& Brewer Ltd.

Anderson, J. (2010). Indigenous/Traditional Knowledge \& Intellectual Property. Retrieved from http://web.law.duke.edu/cspd/pdf lip_indigenous-traditionalknowledge.pdf

ASPACI Associazione per la salvaguardia del patrimonio culturale immateriale (Ed.). (2011). Identificazione partecipativa del patrimonio immateriale. Milano: Centro Stampa BCS. Retrieved from http://www.echi-interreg.eu/assets/uploads/ldentificazione 
partecipativa_Patrimonio_Immateriale_dossier.pdf

Blake, J. (2006). Commentary on the 2003 UNESESO Convention on the Safeguarding of the Intangible Cultural Heritage. Leicester [England]: Institute of Art and Law.

Bonato, L., \& Viazzo, P. P. (Eds.). (2013). Antropologia e beni culturali nelle Alpi. Alessandria: Edizioni dell'Orso.

Brown, M. F. (2005). Heritage Trouble: Recent Work on the Protection of Intangible Cultural Property. International Journal of Cultural Property, 12(01), 40-61.

Hobsbawm, E., \& Ranger, T. O. (1983). The Invention of Tradition. Cambridge University Press.

Kirshenblatt-Gimblett, B. (2004). Intangible Heritage as Metacultural Production. Museum International, 56(1-2), 52-65.

Kurin, R. (2007). Safeguarding Intangible Cultural Heritage: Key Factors in Implementing the 2003 Convention. International Journal of Intangible Heritage, 2, 10-20.

Munjeri, D. (2004). Tangible and Intangible Heritage: from difference to convergence. Museum International, 56(1-2), 12-20.

Nas, P. J. M. (2002). Masterpieces of Oral and Intangible Culture: Reflections on the UNESCO World Heritage List with CA $\vec{s}$ comment. Current Anthropology, 43(1), 139-148.

Schuster, M. J. (2002). Making a List and Checking it Twice: The List as a Tool of Historic Preservation. Retrieved from http://culturalpolicy.uchicago.edu/papers/workingpapers/ Schuster14.pdf

UNESCO. (2003). Convention for the Safeguarding of the Intangible Cultural Heritage. Retrieved from http://unesdoc.unesco.org limages/0013/001325/132540e.pdf

Valentin, E. (2013). Intangible Cultural Heritage and Museums: Experiences from the Project E.CH.I. In L. Bonato \& P. P. Viazzo (Eds.), Antropologia e beni culturali nelle Alpi. Alessandria: Edizioni dell'Orso.

Vecco, M. (2010). A definition of cultural heritage: From the tangible to the intangible. Journal of Cultural Heritage, 11(3), 321-324

Website of the E.CH.I. project http://www.echi-interreg.eu/

Website of the Intangible Search http://www.intangiblesearch.eu/ 